\title{
OS BASTIDORES DA REFORMA UNIVERSITÁRIA DE 1968
}

\author{
José CARLOS RotheN
}

\begin{abstract}
RESUMO: Com o presente estudo busca-se contribuir para a compreensão do processo de elaboração da Reforma Universitária de 1968 e da ação de um dos grupos, formado por parte dos conselheiros do Conselho Federal de Educação, que teve significativa participação na elaboração da Reforma Universitária e que tradicionalmente não é considerado nas pesquisas realizadas sobre o período. Visando mostrar que no seio do governo militar havia um embate sobre os caminhos que deveriam ser dados a Reforma Universitária, faz-se uma comparação entre o relatório produzido pela Comissão Meira Mattos e o produzido pelo Grupo de Trabalho da Reforma Universitária. Conclui-se que o Conselho, ou pelo menos parte dele, utilizou a habilidade política para aproveitar das oportunidades do contexto para participar, nos bastidores da Reforma, da elaboração do modelo de universidade implantado no Brasil na década de 1960.
\end{abstract}

Palavras-chave: Reforma universitária. Conselho Federal de Educação. Universidade.

\section{THE BACKSTAGE OF THE 1968 UNIVERSITY REFORM}

ABSTRACT: This text aims to help understanding the elaboration of the university reform in 1968 and the action of one specific group, formed by some members of the Federal Education Council, which had significant participation in the elaboration of the university reform, though this is not traditionally taken into account by researches. In order to demonstrate that, in the military government, there was some disagreement about the ways the university reform should be carried out, we make a comparison between the report

Doutor em Educação e professor do Programa de Pós-Graduação do Centro Universitário do Triângulo (UNITRI).E-mail: josecarlos@rothen.pro.br Site: www.rothen.pro.br 
produced by the Meira Mattos Commission and the one produced by the University Reform Work Group. We conclude that the Council, or at least part of it, used its political ability to take advantage of the opportunities offered by the context and to participate, from the backstage, in the elaboration of the university model implanted Brazil in the 1960s.

Key words: University reform. Federal Education Council. University.

presente trabalho é resultado da pesquisa referente à atuação do Conselho Federal de Educação (CFE) na elaboração da legislação da Reforma Universitária de 1968. Utiliza-se como hipótese de trabalho que o CFE, entre os anos de 1962 e 1966, atuou de forma a implantar uma reforma universitária mediante a criação de jurisprudência e que a partir do ano de 1967 participou da elaboração de legislação para o ensino superior.

O CFE foi instituído pela lei n. 4.024/1961, conhecida como a LDB/1961, e teve a sua instalação no ano de 1962. A discussão, a elaboração e a aprovação da LDB/1961 ocorreram entre os anos de 1947 e 1961. O período de elaboração dessa lei teve como marca principal o acirrado confronto entre os escolanovistas e os católicos. As diferentes posiçôes no período de discussão da LDB/1961 se diferenciavam em relação às seguintes questóes: centralização ou não pela União do processo educativo, a defesa da escola pública versus a escola privada e a vinculação ou não da educação ao desenvolvimento econômico.

No ano de 1968, diante das reivindicaçôes do movimento estudantil, são instaladas, pelo governo militar, sucessivamente, duas comissões para apresentarem propostas para conter a onda de agitações e para formular um conjunto de soluções realistas para a universidade brasileira: a Comissão Meira Mattos e o Grupo de Trabalho da Reforma Universitária. Normalmente, a instalação das duas comissóes é compreendida como complementar.

No presente trabalho, discute-se a hipótese de que elas são decorrentes de arranjos políticos diferentes. Tomam-se aqui como objeto de estudo os relatórios das duas comissões. Mediante a comparação dos conteúdos presentes neles, discutir-se-á a hipótese de que a elaboração do conteúdo da Reforma Universitária de 1968 é marcado por conflito dentro do governo militar. 
Com o presente estudo, busca-se contribuir para a compreensão do processo de elaboração da Reforma de 1968 e da ação de um dos grupos, formado por parte dos conselheiros do CFE, que teve significativa participação na elaboração da Reforma Universitária e que tradicionalmente não é considerado nas pesquisas realizadas sobre o período.

O texto é dividido em quatro momentos: no primeiro, será apresentada a atuação do CFE na fase aqui denominada jurisprudencial, de 1962 a 1966. O segundo trata da atuação de parte do Conselho na elaboração da legislação referente à estrutura e à organização da universidade brasileira; o terceiro apresenta um estudo comparativo entre os relatórios da Comissão Meira Mattos e do Grupo de Trabalho da Reforma Universitária. No último momento, apresentam-se os trâmites no Congresso Nacional da lei da Reforma Universitária.

\section{Legislando por jurisprudência}

A Lei de Diretrizes e Bases da Educação (LDB), aprovada pelo Congresso Nacional no ano de 1961, apresenta diversas lacunas. Uma delas é a definição da implantação do sistema departamental: no artigo 78 definia-se que os alunos teriam representação no conselho departamental e nos outros órgãos decisórios. Em nenhum outro ponto da LDB/1961 foi definida a existência dos departamentos. Assim sendo, tinha-se a questão: Por estar prevista a representação estudantil nesse conselho, isso implicaria ou não na existência dos departamentos?

As diversas lacunas da LDB permitiram que os conselheiros do CFE, nos pareceres sobre a aprovação dos estatutos das universidades, discutissem o modelo de universidade a ser implantado no Brasil. Entre os anos de 1962 - no qual o CFE foi instalado - e 1966, o Conselho assumiu a postura de propor modelos educacionais, mediante a elaboração de doutrinas ${ }^{1}$ e jurisprudência ${ }^{2}$ ao emitir parecer técnico sobre os temas apresentados à sua análise (Rothen, 2004). Esta fase é nomeada, aqui, como jurisprudencial, pois o Conselho, nos pareceres referentes à aprovação dos estatutos das universidades, buscou estabelecer um modelo de universidade a partir das suas reiteradas decisões.

Os conselheiros tinham a consciência de que, mediante seus pareceres, estavam criando legislação, mesmo quando isso significasse 
alterar a legislação em vigor. O conselheiro Valnir Chagas, em depoimento a Buffa e Nosela (1991, p. 131-132), exemplifica esta postura:

A única coisa boa que tinha naquela lei [LDB/1961] era o art. 18, de que a gente usou e abusou. Era o "principio de flexibilidade", e com o nome de flexibilidade fazíamos tudo; por exemplo, lembro-me como interpretamos os arts. 16, 26 e 36 . O art. 16 dizia que a escola primária tinha quatro séries. $\mathrm{O}$ art. 26 dizia que cabia ao Conselho Estadual reconhecer a escola primária, e o art. 36 dizia que, para entrar no ginásio, era preciso exame de admissão em que ficasse evidenciada uma satisfatória educação primária. Aí, então, eu interpretei da maneira seguinte: se uma pessoa faz quatro anos de escola primária na forma do art. 16, num estabelecimento reconhecido na forma do art. 26, ela tem satisfatória educação primária, não precisa de exame de admissão. Isso é chicana, mas passou.

O conselheiro Maurício Rocha e Silva, em estudo especial apresentado no ano de 1963 sobre a pertinência do sistema de cátedra, defendeu explicitamente que o CFE teria a tarefa de formular e alterar a legislação. Em suas palavras,

Não nos devemos confirmar ao limitado papel de burocratas procurando em estatuto e regimentos das universidades ou escolas isoladas pequenos defeitos que colidem com a Lei, mas devemos doutrinar, explicar, interpretar e procurar transmitir ao público tais estudos ou explicações, para que possam contribuir para a elaboração da Reforma Universitária Brasileira e, portanto, é de nossa alçada, quase diria suprema, analisar e procurar modificar toda a legislação brasileira que colida com o desenvolvimento do ensino e sua elevação aos padrões internacionais, função atribuída pelo presidente da República a este Conselho no veto ao art. 75 da Lei de Diretrizes e Bases. (Silva, 1963, p. 153-154)

Os princípios que nortearam a Reforma Universitária de 1968 foram discutidos no Conselho desde a sua instalação em 1962. Isso se torna patente na apresentação dos pareceres do CFE por Maria Auxiliadora Nicolato (1986). Nas discussões destacam-se os seguintes temas: a autonomia universitária, institutos centrais, desenvolvimento da pesquisa na universidade, indissociabilidade entre ensino e pesquisa, os ciclos básico e profissional, o tempo integral e a instituição da carreira do magistério. Dos princípios fundamentais da Reforma de 1968, o Conselho não estabeleceu consenso apenas sobre a substituição do sistema de cátedras pelo sistema departamental e sobre a adoção do sistema de créditos. 
Em relação ao primeiro princípio, ocorreram inúmeras discussões no Conselho, sobre o segundo há apenas uma referência nos pareceres do Conselho.

A proposta de atuação do CFE mediante o estabelecimento de jurisprudência não diminui com o golpe militar de 1964. Os militares encontraram:

(...) um sistema jurídico-administrativo consolidado no que se refere à educação. Esse sistema não se apresentava como um problema para o governo militar. Tanto a Reforma Universitária realizada em 1968 (sobre a organização do ensino superior) quanto a Reforma do Ensino de $1^{\circ}$ e $2^{\circ}$ graus, a partir de 1971, mantiveram essa estrutura utilizando-se plenamente dela para alcançar seus objetivos. (Martins, 2000, p. 68)

É interessante notar que o CFE não foi dissolvido com a instauração do regime militar. A pergunta que se faz é sobre sua vinculação com os militares. Por que eles não viam a atuação do Conselho como perigosa ao regime? No momento em que ocorreu o golpe de 1964, muitos intelectuais o consideraram como apenas um momento de reordenação do país e que, em breve, tudo voltaria à normalidade. ${ }^{3}$ Valnir Chagas relata a Buffa e Nosella (1991, p. 163) a sua posição:

Eu mesmo nunca usei a palavra Revolução, esperei que ela fosse e não foi. E, então, eu apenas convivi. Para falar sinceramente, não acreditei, em nenhum momento, mas, acho que tinha que se fazer o que pudesse. A minha geração só teve de liberdade, mesmo, os anos de governo de Juscelino Kubitschek, desde que nasci. Se a gente for esperar, não faz nada, e, mesmo assim, o JK foi de certo modo autoritário, fez Brasília "na marra". De maneira que a gente vive no Brasil como ele é, se a gente for esperar um Brasil, comme il faut, a gente nunca vai fazer nada. Você sabe o que é trabalhar em termos de escola única, numa lei de 1970 e poucos, no governo de Médici?

A não identificação, naquele momento, de que se tratava de um golpe de Estado ou de uma possível adesão incondicional ou, ainda, a postura de fazer o que fosse possível permitiu que o CFE não fosse extinto durante o regime militar e aumentasse as suas atribuições. Segundo Paulo Nathanael Pereira de Souza (2001, p. 43), “a Lei 5.540/1968 e o Decreto-Lei 464/1969 atribuíram mais algumas competências ao CFE, tal 
como, por exemplo, ser o intérprete nacional da LDB, o que veio a fortalecê-lo sobremaneira”.

\section{A fase legislativa do CFE: os Decretos-Lei n. 53/1966 e n. 252/1967}

O Executivo, desejando aumentar o controle sobre as instituições federais, e coerente com a opção de aumentar o dirigismo, solicitou, mediante "Aviso Ministerial", que o CFE elaborasse "anteprojeto de lei que promovesse a reestruturação das universidades federais" (Nicolato, 1986, p. 135). Dois dias após o Aviso, o Conselho aprovou o Parecer/Indicação n. 442/1966 elaborado por Valnir Chagas. Neste documento, apresentou-se a proposta de um anteprojeto de lei que, com pequenas alteraçôes de redação, se constituiu no Decreto-Lei n. 53/1966. Nicolato (1986, p. 135 136) interpreta que foi possível a Valnir Chagas elaborar a Indicação em tempo reduzido, pelo fato do conselheiro apenas sistematizar os debates que vinham ocorrendo no Conselho no período de 1962 a 1966.

A estrutura do Decreto-Lei n. 53/1966 manteve coerência com a postura do CFE em não pretender normalizar em detalhes a organização das universidades, pois apenas estabeleceu a doutrina da organização das universidades federais. Segundo Nicolato, o Decreto-Lei n. 53/1966 (chamado aqui de doutrinário) de imediato não alcançou os resultados esperados. A primeira proposta de reestruturação apresentada ao CFE, a da Universidade Federal do Rio de Janeiro (UFRJ), não atendia aos princípios expressos no citado Decreto-Lei.

Foi nomeada, para elaborar um novo anteprojeto de lei, a seguinte comissão de conselheiros: Clóvis Salgado, Durmeval Trigueiro, Valnir Chagas, Newton Sucupira e Rubens Maciel. A proposta da comissão constitui-se num projeto normalizador. Nicolato (op. cit., p. 140-141) apresenta os aspectos básicos do Decreto-Lei n. 252/1967:

1. Consagração dos princípios fixados no Decreto-Lei 53/66, limitando-se ao estabelecimento de normas complementares a seus dispositivos.

2. Instituição obrigatória do sistema departamental e a conseqüente eliminação da cátedra autônoma, permanecendo, contudo, a figura do catedrático como um posto da carreira do magistério.

3. Definição do departamento como "a menor fração" da estrutura universitária para todos os efeitos de organização administrativa e didático-científica e de distribuição de pessoal. 
4. Especificação das competências e composição dos departamentos e da forma de preenchimento de sua chefia.

5. Definição das áreas fundamentais que deveriam servir de base para a estruturação dos sistemas de ensino e pesquisa básico e profissional: ciências matemáticas, físicas, químicas e biológicas, geociências, ciências humanas, filosofia, letras e artes.

6. Atribuição da coordenação didática de cada curso a um colegiado constituído por representantes dos departamentos que participassem do ensino nesses cursos.

7. Possibilidade de criação de órgãos setoriais que congregassem várias unidades de uma mesma área de conhecimento, com poderes administrativos.

8. Possibilidade de criação, a critério das universidades, de um ciclo de estudos que precedesse à opção profissional.

9. Possibilidade de criação de órgãos suplementares de natureza técnica, cultural, recreativa e de assistência ao estudante.

10. Definição da função de extensão a ser desenvolvida pelas universidades, através de cursos e serviços oferecidos à comunidade, passível de contar com uma coordenação própria.

11. Possibilidade de manutenção como unidades universitárias dos institutos especializados já existentes que tivessem atingido alto grau de desenvolvimento.

Nesse Decreto-Lei, percebe-se que foram normalizados os principais pontos sobre os quais o CFE já havia criado jurisprudência ou tinha se detido em longos debates. Além de os pareceres atenderem à solicitação do Executivo, é relevante notar que conselheiros destacados na luta pela autonomia universitária e defensores da idéia de que a reforma universitária deveria ocorrer a partir das universidades alteraram a sua posição e passaram a defender a reforma universitária mediante legislação própria. Esse é o caso de Newton Sucupira, que defendeu a elaboração dos referidos decretos-lei no "II Seminário sobre Assuntos Universitários", promovido pelo CFE para dirimir dúvidas sobre a legislação. Ele assim argumentou:

Essa providência legal parte de um duplo pressuposto: primeiramente, a impossibilidade de se operar a transformação do conteúdo, objetivos e processos do ensino superior nos quadros estruturais vigentes; em segundo lugar, a necessidade de quebrar as resistências anti-reformistas, dentro da 
universidade, compelindo-a a reestruturar-se em função de critérios racionais para ajustar-se às tarefas da universidade moderna. (Sucupira, 1968, p. 92)

\section{A Lei n. 5.540/1968: a comissão Meira Matos, o GTRU e o CFE}

No final do ano de 1967 e no ano de 1968, o governo militar visando controlar o movimento estudantil e enfrentar o problema dos excedentes do exame vestibular ${ }^{4}$ - institui, num primeiro momento, a Comissão Meira Mattos5 (12/1967) e, posteriormente, o Grupo de Trabalho da Reforma Universitária ${ }^{6}$ (GTRU - 07/1968). As instalações da Comissão e do GTRU são compreendidas normalmente como pertencentes ao mesmo movimento interno do governo militar. A partir da pesquisa realizada, contesta-se esta interpretação levantando a hipótese de que a Comissão e o GTRU foram instalados por arranjos políticos diferentes. Esta hipótese tem a seguinte fundamentação:

a) Os membros da Comissão e do GTRU eram diferentes, sendo que na primeira não constava a participação do Ministério da Educação e Cultura, nem de representantes do Ministério do Planejamento e da Fazenda, enquanto que o GTRU foi presidido pelo ministro da Educação e contou com representantes do Ministério do Planejamento e da Fazenda.

b) A parte do Relatório da Comissão Meira Mattos, destinada a relatar as atividades desenvolvidas, transmite a impressão de que a Comissão se apresentava como interventora no Ministério da Educação e Cultura.

c) O CFE não participou da Comissão Meira Mattos; o GTRU, por sua vez, contou com membros do CFE (Newton Sucupira e Valnir Chagas) que atuaram ativamente na fase jurisprudencial e na elaboração dos Decretos-Lei. É relevante considerar que o Decreto n. 62.937, de 2 de julho de 1968, que institui o GTRU, previa que o CFE seria "ouvido nas matérias relacionadas com suas atribuiçōes específicas”. Dessa forma, a influência concedida ao CFE na elaboração da proposta da reforma universitária não se resumiu à nomeação de conselheiros como membros do GTRU, mas se estendeu à previsão legal de que o Conselho fosse ouvido. 
d) A Comissão Meira Mattos, em seu Relatório, entre outras teses, defendia que a atuação do CFE seria uma das causas da não expansão das vagas no ensino superior e que o poder do CFE seria maior que o do Presidente da República. Por sua vez, o GTRU ressaltou o papel central do CFE nas políticas públicas para a educação.

Os trabalhos desenvolvidos pela Comissão Meira Mattos e o realizado pelo Grupo de Trabalho da Reforma Universitária (GTRU) tiveram, por um lado, o caráter de complementaridade e, por outro, de contraposição. A continuidade se encontra, primeiro, no aspecto de que o Relatório Meira Mattos apontava, em suas conclusões, para a necessidade de ser revista a legislação educacional, o que supõe a instauração de um grupo de trabalho para tal fim; segundo, que muitas das idéias que estão presentes no Relatório Meira Mattos estão também presentes no Relatório do GTRU. A contraposição consiste no fato de que em várias partes do Relatório do GTRU encontram-se respostas e críticas implícitas ao Relatório Meira Mattos e a rejeição de algumas das suas proposiçōes centrais. A comparação entre os dois relatórios, que será apresentada aqui, tem por objetivo mostrar que a diferença marcante entre eles consiste basicamente no papel que é atribuído ao CFE na formulação da proposta da reforma e da sua implantação.

\section{a) Os objetivos e as estruturas dos relatórios}

O Relatório Meira Mattos, no seu início, afirma que o objetivo principal da criação da Comissão Especial é o de

(...) emitir pareceres sobre as reivindicaçôes, teses e sugestōes referentes às atividades estudantis, assim como quanto à proposição de medidas capazes de possibilitar a melhor aplicação das diretrizes governamentais no âmbito das entidades de ensino, visando o seu efeito sobre o corpo discente. (Relatório Meira Matos, 1969, p. 199-200. Grifo nosso)

O Relatório Meira Mattos foi dividido em duas partes. Na primeira, foram apresentadas ações tomadas pela Comissão Especial no sentido de buscar soluções para problemas particulares. Por exemplo, relatou os contatos feitos pelo presidente da Comissão com o ministro da Fazenda para liberar os recursos referentes aos convênios feitos com as universidades, em 1967; relatou ainda que foi solicitada ao ministro 
da Fazenda a compra de um imóvel para a instalação da Faculdade de Letras da UFRJ. Na segunda parte do relatório foram apresentados os "pontos críticos do sistema educacional que interferem direta ou indiretamente com as aspirações da juventude estudantil” (idem, ibid., p. 207).

O Relatório do GTRU, na apresentação dos objetivos do Grupo de Trabalho, apontou a primeira diferença entre os trabalhos realizados por ele e pela Comissão Meira Mattos:

Os termos do decreto [62.937, de julho de 1968] são bastante explícitos e definem uma tarefa concreta e objetiva. Não se trata, pois, de formular um diagnóstico da presente crise universitária, nem mesmo de traçar os delineamentos de uma reforma, e sim propor um repertório de soluções realistas e de medidas operacionais que permitam racionalizar a organização das atividades universitárias, conferindo-lhes maior eficiência e produtividade. (Reforma, 1969, p. 122. Grifos nossos)

Interpreta-se, aqui, que nesse fragmento de texto do Relatório o GTRU assumiu a postura explicita de contraposição à Comissão Meira Mattos, ao defender que a reforma universitária a ser realizada não deveria ser casuística, isto é, não deveria ser realizada apenas para resolver problemas imediatos, como seria o caso do que é proposto no Relatório Meira Mattos.

A estrutura do Relatório do GTRU é mais bem organizada do que o da Comissão Meira Mattos, não havendo repetições de assuntos e de teses. Esse Relatório tratou dos seguintes temas: concepção geral da reforma, regime jurídico e administrativo, estrutura, articulação da escola média com a superior, cursos e currículos - regime escolar, corpo docente, implantação da pós-graduação, corpo discente, expansão do ensino superior e recursos para a educação.

\section{b) Os Decretos-Lei n. 53/1966 e n. 252/1967}

Os dois Relatórios defenderam que a estrutura da reforma universitária já estava presente nos Decretos-Lei n. 53/1966 e n. 252/1967, que reformularam as universidades federais, e que os princípios presentes neles estavam sendo adotados pelas instituiçóes privadas. Os Relatórios diferenciam-se na avaliação da aplicação prática dos Decretos. No Relatório Meira Mattos foi criticado o fato de que a reforma universitária 
estava sendo lenta e desordenada, por isso mesmo não atenderia às necessidades da realidade brasileira. Segundo este Relatório, tinha-se “(...) a necessidade de atender uma demanda cada vez maior correspondente aos ritmos de crescimento populacional; o imperativo de adaptar os cursos e currículos às imposições do desenvolvimento nacional, ajustandoos às características que singularizam o nosso país" (Relatório Meira Matos, 1969, p. 224)

Por sua vez, no Relatório do GTRU foi apresentada a concepção de que a adoção espontânea da estrutura proposta nos Decretos-Lei indicava que bastaria generalizar para todas as instituições o modelo já consolidado. Nos termos do Relatório, “(...) já é tempo de generalizar as soluções adotadas numa concepção de universidade que substitua, como política a seguir de agora por diante, a mera justaposição de faculdades a que, em ultima análise, se reduz a definição contida na Lei de Diretrizes e Bases" (Reforma, 1969, p. 129).

\section{c) A atuação do Conselho Federal de Educação}

A Comissão Especial (Meira Mattos) e o GTRU tinham visões antagônicas em relação ao papel do CFE. Enquanto a Comissão Meira Mattos compreendia que a atuação do CFE foi um dos pontos críticos para a expansão do ensino superior, reivindicado pela "juventude estudantil”, o GTRU, no seu relatório, deixou transparecer que o CFE teria função importante na elaboração e na implantação da reforma universitária.

A Comissão Meira Mattos apontou que os poderes "excessivos" atribuídos ao CFE eram uma das causas da "crise de autoridade" pela qual estaria passando no momento. Como foi visto acima, encontra-se no Relatório o seguinte diagnóstico:

A soma de poderes concedidos ao Conselho Federal de Educação, pela Lei de Diretrizes e Bases, é de tal ordem que não só o ministro, como o próprio presidente da República, em assuntos ou questôes de natureza pedagógica e educativa, devem solicitar o parecer daquele Conselho, o que representa uma inversão da ordem hierárquica no âmbito do executivo. (Relatório Meira Matos, 1969, p. 214)

O GTRU, sem afirmar explicitamente, defendeu que as idéias que estavam presentes no seu Relatório já teriam sido apresentadas pelo CFE. 
Isso se torna patente nas diversas citações de pareceres e de indicações do CFE para fundamentar as posições defendidas. Identifico as seguintes citações do Conselho:

- Indicação n. 48/1967, que se refere à estrutura das universidades (p. 129) e à articulação do ensino médio e superior (p. 130);

- Parecer n. 281/1967, que dispóe sobre o fim da cátedra e a implantação de departamentos (p. 136);

- Parecer n. 977/1965, que define a natureza dos cursos de pósgraduação (p. 137).

Em relação à implantação da reforma universitária, o GTRU defendeu que o CFE deveria

- Ter as suas atribuições aumentadas para que pudesse normalizar em relação aos currículos mínimos tanto dos cursos que preparariam para as profissões reguladas em lei, como para as não reguladas, desta forma seria possível garantir a necessária flexibilidade do sistema (p. 132);

- criar as normas para a pós-graduação (p. 139);

- ter representante em Grupo de Trabalho a ser constituído para identificar as necessidades de aumento de vagas nas áreas prioritárias para o desenvolvimento do país e de promover "entendimentos com as universidades para adoção das medidas necessárias" (p. 144).

- ter representante no Conselho Deliberativo a ser criado para formulação de políticas de maior vulto (p. 149).

$\mathrm{O}$ tratamento diferenciado que o CFE recebeu das duas comissóes reforça a hipótese levantada acima de que ambas são constituídas por arranjos políticos distintos, tendo o arranjo que institui o GTRU, provavelmente, a participação efetiva de membros do CFE.

\section{d) O movimento estudantil}

Nos dois Relatórios encontram-se argumentos em defesa da efetiva participação dos estudantes na vida acadêmica. Contudo, a Comissão 
Meira Mattos considerava que o movimento estudantil estaria controlado por minoria de estudantes de esquerda. No Relatório Meira Mattos foi apontado que, apesar de pesquisas do IBOPE indicarem que a maioria dos estudantes (77\%) afirmaram ser "antiesquerdista", a "liderança democrática autêntica" não estaria suficientemente organizada para contrapor-se ao movimento estudantil de esquerda. Como conseqüência desse diagnóstico, a Comissão considerava que não era momento para a autorização da instalação de entidades estudantis de nível nacional e estadual e propunha que os estudantes não tivessem participação em órgãos colegiados (Relatório Meira Matos, 1969, p. 228-232). Por sua vez, o GTRU afirmou que "O movimento estudantil, quaisquer que sejam os elementos ideológicos e políticos nele implicados, teve o mérito de propiciar uma tomada de consciência nacional do problema e o despertar enérgico do senso de responsabilidade coletiva" (Reforma, 1969, p. 123).

A partir dessa constatação, o GTRU considerava que os estudantes deveriam ter a sua representação reforçada com a participação em todos os órgãos colegiados. Caso contrário, a reforma universitária serviria apenas para "fomentar um clima de desconfiança e de hostilidade". O GTRU compreendia que a institucionalização do diálogo não permitiria que o espírito crítico dos estudantes se transformasse "numa atitude estéril de permanente contestação” (idem, ibid., p. 140).

\section{e) Autonomia universitária}

A diferença de posição nos Relatórios sobre a pertinência da atuação estudantil reflete como foi tratada nos mesmos a questão da autonomia universitária. A Comissão Meira Mattos, tendo como preocupação maior desenvolver mecanismos de controle do movimento estudantil, considerava o cerceamento da autonomia universitária como condição necessária para tanto. A Comissão entendia que, para restaurar a autoridade dos reitores, estes teriam que ser livremente escolhidos pelo Presidente da República, em vez de serem selecionados em uma lista tríplice elaborada pelas congregações das universidades.

A Comissão considerava que estaria havendo abuso no exercício da liberdade de cátedra, pois não existiria instrumento legal que permitisse "fiscalizar pregações em aulas, antidemocráticas e contra a moral, em conseqüência coibir-se os alunos delas decorrentes" (Relatório 
Meira Matos, 1969, p. 221). A Comissão sugeriu que os conteúdos a serem ensinados fossem aprovados pelo departamento ou órgão semelhante.

O GTRU, no seu Relatório, contrapôs-se à proposta da Comissão Meira Mattos. O GTRU defendeu que a reforma universitária ocorreria no entrechoque de tripla dialética: a vertical, entre o Estado e a universidade, a horizontal, entre a comunidade e a universidade, e a interna, que se estabeleceria na relação mestre/aluno. Com a tripla dialética se garantiria que a universidade não se tornaria um ente isolado do meio social (Reforma, 1969 , p. 123-4). O GTRU compreendia que o governo da universidade deveria conciliar a participação dos professores, alunos e comunidade externa. Apesar de manifestar-se a favor da autonomia universitária, o GTRU defendeu a idéia de que a universidade não tinha forças para renovar-se por si mesma e que caberia ao Estado a função de estimulá-la e discipliná-la. $\mathrm{Na}$ proposta do GTRU, o Estado teria a função de instituir os aspectos legais da reforma universitária e as universidades, a de realizá-la de fato. O papel disciplinador seria de responsabilidade do GTRU. A adoção desta proposta foi que permitiu, posteriormente, que o CFE, nas décadas de 1970 e 1980, favorecesse, como mostra o estudo de Dirce Fonseca (1992), a expansão do ensino privado e de estabelecimentos isolados.

\section{f) A instalação de centros de excelência e a expansão universitária}

Tanto a Comissão Meira Mattos como o GTRU, ao analisarem a expansão universitária, considerando a escassez de recursos, propuseram que fossem escolhidos centros de excelência para receberem apoio do Estado. A Comissão Meira Mattos propôs que fossem escolhidos em cada área geo-educacional os cursos de especialização mais promissores, para neles serem concentrados os recursos financeiros e os professores mais capacitados (Relatório Meira Matos, 1969, p. 237).

O GTRU defendeu que o governo federal deveria escolher as universidades que já tivessem o mínimo de desenvolvimento que permitisse a instalação de cursos de pós-graduação, para transformá-los em centros regionais de pós-graduação, os quais teriam a função de centros de formação de professores de outras universidades e de treinamento avançado no campo da tecnologia (Reforma, 1969, p. 139). Assim, pode-se afirmar que nos dois Relatórios é proposta a criação de um sistema universitário duplo: instituições de excelência e instituições de formação profissional. 


\section{g) Ensino superior e desenvolvimento econômico}

Nos dois Relatórios, o ensino universitário foi compreendido como condição para o desenvolvimento do país. As principais teses defendidas em ambos os relatórios são:

- Haveria carência de recursos humanos para o desenvolvimento do país;

- a universidade não estaria atendendo as demandas do mercado de trabalho e da evolução tecnológica; haveria necessidade de estar atenta às exigências do mercado de trabalho;

- a expansão do ensino superior deveria ser planejada para atender as áreas prioritárias para o desenvolvimento do país;

- elaboração de um planejamento para a expansão do ensino superior, evitando assim a concentração de cursos de uma mesma área;

- uma das funções da universidade seria a de desenvolver tecnologia.

Nos dois documentos, encontra-se a veemente ressalva de que, apesar de a educação ter papel fundamental para o desenvolvimento econômico, a sua função não se resumiria à formação de profissionais, mas se estenderia à formação do indivíduo. Nos termos da Comissão Meira Mattos, "Educação como instrumento de formação de uma lúcida e esclarecida mentalidade democrática, visando a projetar na Educação a fé nos valores espirituais e morais da nacionalidade" (Relatório Meira Matos, 1969, p. 210). Nos termos do GTRU, “(...) cresce também o convencimento de que a educação universitária corresponde a uma exigência de formação da pessoa, acima de toda concepção puramente profissional ou mercantil da cultura" (Reforma, 1969, p. 123).

\section{h) Ciclo básico}

A idéia da implantação de um ciclo básico comum a diversas áreas está presente nas duas propostas, diferenciando-se apenas a justificativa para a sua instalação. A Comissão Meira Mattos entendia que a implantação desse ciclo permitiria a utilização das vagas ociosas, amenizando-se 
assim o problema da falta de vagas (Relatório Meira Matos, 1969, p. 227). O GTRU, por sua vez, afirmou que o ciclo básico teria tripla função: “(a) recuperar falhas evidenciadas pelos vestibulares no perfil de cultura dos novos alunos, (b) orientar para escolha das carreiras e (c) proporcionar estudos básicos para os ciclos ulteriores" (Reforma, 1969, p. 131).

\section{i) Cursos de curta duração e a pós-graduação}

Os cursos de curta duração foram apresentados, nos dois Relatórios, como compensação da formação rápida de profissionais que atendesse ao mesmo tempo as necessidades de mercado de trabalho e a reivindicação de vagas no ensino superior. Nas duas propostas encontram-se três tipos de cursos: os de curta duração, os cursos com duração prolongada e a pósgraduação.

A pós-graduação, na proposta da Comissão Meira Mattos, era destinada "aos alunos mais capacitados que desejem continuar os seus estudos" (Relatório Meira Matos, 1969, p. 227). No relatório GTRU foi exposto que a instalação dos cursos de curta duração atenderia ao reclame do mercado de trabalho, e que o atendimento a esta reivindicação deveria ter a contrapartida da implantação dos cursos de pós-graduação para produzir o know-how necessário para o desenvolvimento do país (Reforma, 1969, p. 137).

\section{j) Financiamento do ensino superior}

Os Relatórios, ao tratarem o financiamento do ensino superior, compartilham das seguintes propostas: racionalização do uso dos recursos disponíveis, aumento do investimento do governo federal na educação, planejamento da expansão das universidades, evitando desperdícios com a duplicidade de cursos em uma mesma área, liberação pelo governo federal dos recursos destinados à educação e cobrança de anuidade dos estudantes de renda familiar mais alta. O GTRU, no seu Relatório, ao contrário da Comissão Meira Mattos, apresentou longa lista de medidas para o financiamento da educação.

\section{k) Corpo docente}

Em relação ao corpo docente, novamente se encontram nos dois Relatórios propostas semelhantes por motivos diferentes. Em ambos, foi proposta a implantação do Estatuto do Magistério e o fim da cátedra. 
A Comissão Meira Mattos considerava que o Estatuto do Magistério, acompanhado do aumento de salário, permitiria que os docentes estivessem mais próximos dos estudantes, diminuindo assim a frustração estudantil, e que os pesquisadores não abandonassem o serviço público (Relatório Meira Matos, 1969, p. 217-218). A Comissão não apresentou explicitamente a proposta do fim da cátedra, mas ao tratar da liberdade de cátedra, como vimos acima, avaliava que a criação dos departamentos permitiria o controle do que seria ensinado.

O GTRU entendia que a implantação do Estatuto do Magistério seria condição para que a universidade atendesse a sua missão de indissociabilidade entre o ensino e a pesquisa. Para que a carreira do magistério valorizasse a produção intelectual do professor, seria necessário que ela fosse aberta e, para tanto, seria também necessário que a cátedra fosse extinta. Apesar da veemente defesa da implantaçăo da dedicaçăo exclusiva para todos os docentes, o GTRU considerava não factível a sua imediata implantação, pois o seu custo não seria suportável, principalmente para as instituições particulares (Reforma, 1969, p. 134-6). A adoção desta proposição permitiu que a rede particular se expandisse, sem efetiva implantação do regime de dedicação exclusiva.

\section{1) Expansão do ensino superior}

Tanto a Comissão Meira Mattos como o GTRU consideravam que a necessidade de expansão não se resumisse ao ensino superior, mas sim ao sistema como um todo. Compartilhavam da idéia de que a expansão deveria seguir um planejamento para atender à necessidade do mercado de trabalho e a aspiração da juventude em relação ao ensino superior. A Comissão Meira Mattos apontou que, para ocorrer a expansão, seria necessária estreita vinculação entre o MEC e as universidades; para isso, seria necessária a nomeação dos reitores pelo Presidente da República. Considerava ainda a necessidade de reformar a remuneração docente e acelerar a reforma universitária (Relatório Meira Matos, 1969, p. 221-223).

O GTRU enfatizou que a escola de segundo grau precisaria preparar os indivíduos para o trabalho e que o ensino superior deveria ser destinado apenas àqueles que são mais aptos para cursá-lo. Assim, o ensino de segundo grau conteria a demanda por ensino superior, não sendo necessário o aumento de suas vagas (Reforma, 1969, p. 141-143). 


\section{O caminho da lei}

O Relatório do GTRU continha um anteprojeto de lei geral, cinco anteprojetos de leis especiais, sete anteprojetos de decretos e quatro recomendações, que em linhas gerais constituíram a legislação que implantou a reforma legal.

Entre 16 de agosto e 24 de setembro de 1968, antes de enviar a proposta definitiva ao Presidente da República, os ministros da Educação e Cultura, Planejamento, Fazenda e Justiça fizeram alterações nos anteprojetos elaborados pelo GTRU. As alteraçóes foram baseadas parcialmente em sugestôes do CFE e por iniciativa dos ministros. As alteraçôes dos ministros visavam fortalecer a capacidade de controle do poder central (Nicolato, 1986, p. 303-306). O projeto de lei foi enviado ao Congresso Nacional em 7 de outubro de 1968, integrando um pacote de sete mensagens "para serem discutidas e votadas em regime de urgência, portanto, pelo prazo de quarenta dias, findo o qual seriam aprovados por decurso de prazo" (Saviani, 1988, p. 87).

O fato do Executivo não utilizar decretos-lei, mas sim de enviar ao Congresso Nacional anteprojetos de lei é interpretado por Germano (1994, p. 95) como uma tentativa dos militares de obter um mínimo de consenso. Na mesma linha de raciocínio, Saviani (1988, p. 99) entende que "o regime autoritário resultante do golpe militar de 1964 constituiu uma ditadura envergonhada de si mesma”. Apesar de, inicialmente, alguns deputados considerarem o tempo para a discussão e a aprovação do projeto escasso, o Congresso Nacional cumpriu o seu papel legitimador, tanto que

(...) o projeto recebeu 133 emendas, às quais se acrescentavam mais 9 apresentadas pelo relator, perfazendo um total de 142. Das 133 emendas, 77 foram sumariamente rejeitadas pelo relator, 3 foram em parte rejeitadas e em parte sub-emendadas, 37 foram sub-emendadas e apenas 16 foram acolhidas integralmente. (Saviani, 1988, p. 92)

O projeto aprovado pela Câmara recebeu vetos presidenciais. Os vetos ao projeto aprovado tornam claro que o Executivo apenas desejava a legitimação do projeto pelo Legislativo e não a sua discussão, tanto que foram vetados 
(...) onze dos quinze dispositivos acrescentados pelos congressistas, bem como seis das nove alteraçōes por eles processadas, mantendo-se apenas as modificações que representavam particularidades ou reforço da proposta original (...). Se dúvidas houvesse sobre o fato de ter o Executivo pretendido meramente cumprir uma formalidade ao enviar o projeto de lei ao Legislativo, a edição do Decreto-lei n. 464, em 11 de fevereiro de 1969 , de pronto as demoveria. É que por este Decreto-lei, sancionado menos de três meses após a lei 5.540, o Presidente da República, avocando os poderes excepcionais que lhe fora autorgados [sic] pelo Ato Institucional n. 5, recompôs o seu projeto inicial de Reforma, impondo exatamente aqueles dispositivos que dele haviam sido excluídos pelos parlamentares ou pelos vetos da Presidência, face às modificações neles introduzidas pelo Congresso. (Nicolato, 1986, p. 347)

A Lei n. 5.540/68 é, por um lado, fruto das discussões que se realizavam sobre o modelo de universidade a ser adotado no país, discussões que nortearam a ação do CFE na fase jurisprudencial, como na elaboração dos Decretos-Lei n. 53/66 e n. 252/67, por outro, fruto da vontade dos militares, mediante uma legislação centralizadora, de imporem à sociedade civil um consenso sobre o modelo de universidade e diminuírem as resistências internas das universidades ao regime militar.

Um dos resultados da participação do CFE na elaboração da reforma universitária foi que, ao contrário da conclusão da comissão Meira Mattos, "A lei 5.540/68 e o Decreto-lei 464/69 atribuíram mais algumas competências ao CFE, tal como, por exemplo, ser o intérprete nacional da LDB, o que veio a fortalecê-lo sobremaneira" (Souza, 2001, p. 43).

É relevante considerar que houve efetiva participação de membros do CFE nos grupos de trabalhos de 1969 e 1970, pelos quais foi elaborado o anteprojeto da Lei n. 5.692/71, que reformulou o ensino de primeiro e segundo graus. May Guimarães Ferreira (1990, p. 269) afirma que:

(...) em ambos os grupos, o CFE teve participação ativa através de alguns dos seus membros: Padre Vasconcellos, Celso Kelly, Carlos Pasquale foram indicados no GT de 69, Terezinha Saraiva era membro desse primeiro GT, mas entrou posteriormente para o CFE. Padre Vasconcellos e Valnir Chagas no segundo, Eurídes Brito, que também fazia parte desse GT, só começou a fazer parte do CFE em 1974. 
A influência do CFE, ou pelo menos de alguns de seus membros, nas reformas de 1968 e 1971 ficou patente no fato de Valnir Chagas ter participado do GTRU de 1968 e ter sido o relator do anteprojeto da Lei n. 5.692/71.

\section{Considerações finais}

O Conselho Federal de Educação, logo após a sua instalação, procurou desenhar um modelo de universidade e implantá-lo no Brasil. Como instrumento legal, utilizou-se da jurisprudência gerada nos pareceres emitidos pelo Conselho em relação aos projetos de regimentos das Instituições de Educação Superior e em resposta às consultas feitas a ele. Com esta prática, o CFE tinha como objetivo ser o fórum privilegiado da discussão da Reforma Universitária, isto mesmo após o golpe militar de 1964. Contudo, este fórum de discussão não estabeleceu um diálogo com a sociedade, mas sim promoveu a discussão nos bastidores do governo militar, tanto que os movimentos sociais da época e de parte das pesquisas históricas sobre esse período não perceberem a influência do CFE na elaboração da Reforma Universitária de 1968.

As discussões ocorridas no âmbito do CFE criaram conhecimento acumulado que permitiu, em um primeiro momento, a rápida preparação pelo Conselho dos anteprojetos dos decretos-lei que reformularam as universidades federais e, em um segundo momento, que o GTRU, em escasso tempo, elaborasse os anteprojetos legislativos que, em linhas gerais, constituíram a lei da Reforma Universitária. Nos dois casos, é possível afirmar que as propostas são decorrentes de uma sistematização da jurisprudência estabelecida a partir dos pareceres dos conselheiros.

A pesquisa realizada sobre a atuação do CFE permite concluir que o Conselho, ou pelo menos parte dele, utilizou da habilidade política para se aproveitar das oportunidades do contexto a fim de participar, nos bastidores da Reforma Universitária, da elaboração do modelo de universidade implantado no Brasil na década de 1960. Pelo que foi visto, esta habilidade torna-se patente, primeiro, no fato do Conselho Federal de Educação se manter praticamente com os mesmos membros nomeados antes do golpe militar de 1964; segundo, pela utilização, na fase jurisprudencial, das lacunas da LDB/1961 para desenhar o modelo a ser adotado na legislação da Reforma Universitária de 1968 e, terceiro, na 
capacidade de articulação política em 1968 para neutralizar as conclusões da Comissão Meira Mattos, mediante a sua efetiva participação no Grupo de Trabalho da Reforma Universitária.

\section{Recebido em março de 2006 e aprovado em outubro de 2006}

\section{Notas}

1. Pinho e Nascimento (2000, p. 49) afirmam que a investigação doutrinária tem as seguintes funçôes: "a) como base justificativa e interpretativa do texto legal; b) como fonte supletiva das deficiências e omissões do texto legal; c) como solução das questôes para as quais a lei não fornece elementos; e d) como repositório de princípios que não podem ser submetidos à lei escrita pela própria natureza”.

2. Segundo Pinho e Nascimento (ibid., p. 49), a jurisprudência "expressa-se por meio das sentenças e acórdãos proferidos nas demandas. Essas decisōes, quando tomadas em determinado sentido, passam a ser invocadas como precedentes a serem seguidos".

3. Ver, por exemplo, o depoimento de Roque Spencer Maciel de Barros a Buffa e Nosella (1991, p. 165), no qual ele apresenta a sua adesão inicial ao golpe. Barros afirma que nesse período escreveu artigos defendendo a atuação militar.

4. Horta (1975, p. 179) define a figura do excedente como "aquele que tivesse sido habilitado, mas não tivesse sido selecionado". A não-seleção de um candidato ocorre pelo fato do número de vagas ser menor que o número de candidatos habilitados.

5. Comissão presidida pelo coronel Meira Mattos, do Corpo Permanente da Escola Superior de Guerra, sendo os seus outros membros o professor Hélio de Souza Gomes, diretor da Faculdade de Direito da UfrJ; o professor Jorge Boaventura de Souza e Silva, diretor-geral do Departamento Nacional de Educação; o promotor-público Afonso Carlos Agapito e o coronel-aviador Waldir de Vasconcelos, secretário-geral do Conselho de Segurança Nacional (Fávero, 1977, p. 60).

6. "Foram os seguintes os seus membros efetivos: ministro Tarso Dutra, da Educação e Cultura, como seu presidente; Antônio Moreira Couceiro, professor da Universidade Federal do Rio de Janeiro e presidente do CNPq; pe. Fernando Bastos D’Avila, vice-reitor da PUC/RJ; João Lyra Filho, reitor da Universidade do Estado da Guanabara; João Paulo dos Reis Velloso, representante do ministro do Planejamento; Fernando Riveiro do Val, representante do Ministro da Fazenda; Roque Spencer Maciel de Barros, professor da Universidade de São Paulo, Newton Sucupira, professor e ex-reitor da Universidade Federal de Pernambuco e membro do CFE; Valnir Chagas, professor e diretor da Faculdade de Filosofia da Universidade Federal do Ceará e membro do CFE, e Haroldo Leon Perez, representante do Congresso Nacional" (Nicolato, 1986, p. 272). Os dois estudantes declinaram da nomeação.

\section{Referências}

BUFFA, E.; NOSELLA, P. A educação negada: introdução ao estudo da educação brasileira contemporânea. São Paulo: Cortez, 1991. (Biblioteca da educação. Série 1 - Escola; v. 17).

Educ. Soc., Campinas, vol. 29, n. 103, p. 453-475, maio/ago. 2008

Disponível em <http://www.cedes.unicamp.br> 
FÁVERO, M.L.A. A universidade brasileira: em busca de sua identidade. Petrópolis: Vozes, 1977. 102p.

FERREIRA, M.G. Conselho Federal de Educação: o coração da reforma. 1990. 334f. Tese (Doutorado em Educação) - Faculdade de Educação, Universidade Estadual de Campinas, Campinas.

FONSECA, D.M. O pensamento privatista em educação. Campinas: Papirus, 1992. 224p.

GERMANO, J.W. Estado militar e educação no Brasil: 1964-1965. 2. ed. São Paulo: Cortez, 1994.

HORTA, J.S.B. O Conselho Federal de Educação e o planejamento educacional no Brasil: uma contribuição à história da educação brasileira. 1975. 236f. Dissertação (Mestrado em Educação) - Pontifícia Universidade Católica do Rio de Janeiro, Rio de Janeiro.

MARTINS, M.C. A história prescrita e disciplinada nos currículos escolares: quem legitima esses saberes. 2000. 264f. Tese (Doutorado em Educação) - Faculdade de Educação, Universidade Estadual de Campinas, Campinas.

NICOLATO, M.A. A caminho da lei 5.540/68: a participação de diferentes atores na definição da reforma universitária. 1986. 519f. Dissertação (Mestrado em Educação) - Faculdade de Educação, Universidade Federal de Minas Gerais, Belo Horizonte.

PINHO, R.R.; NASCIMENTO, A.M. A lei. In: Pinho, R.R.; NASCIMENTO, A.M. Instituiçôes de direito público e privado: introdução ao estudo do direito e noções de ética profissional. 22. ed. São Paulo: Atlas, 2000. p. 40-50.

REFORMA universitária: relatório do Grupo de Trabalho. Revista Brasileira de Estudos Pedagógicos, Brasília, DF, v. 50, n. 111, p. 119-175, jul./set. 1968.

RELATÓRIO Meira Matos. Paz e Terra, Rio de Janeiro, v. 4, n. 9, p. 199241, out. 1969 .

ROTHEN, J.C. Funcionário intelectual do Estado: um estudo de epistemologia política do Conselho Federal de Educação. 2004. Tese 
(Doutorado em Educação) - Universidade Metodista de Piracicaba, Piracicaba.

SAVIANI, D. Política e educação no Brasil: o papel do Congresso Nacional na legislação do ensino. 2. ed. São Paulo: Cortez; Campinas: Autores Associados, 1988. 163p.

SILVA, M.R. Universidade sem cátedras: estudo especial. Revista Brasileira de Estudos Pedagógicos, Brasília, DF, v. 40, n. 91, p. 153-159, jul./ set. 1963.

SOUZA, P.N.P. $L D B$ e educação superior: estrutura e funcionamento. 2. ed. São Paulo: Pioneira, 2001. 249p.

SUCUPIRA, N. A reestruturação das universidades federais. Revista Brasileira de Estudos Pedagógicos, Brasília, DF, v. 50, n. 111, p. 83-95, jul./ set. 1968. 